\title{
TEADLASE MORAALSED VALIKUD KULTUURIMÄLU LOOMISEL
}

\author{
MARI SARV
}

$\mathrm{A}$ rtikli eesmärgiks on rahvaluuleteaduse näitel analüüsida teadlase valikuid kultuuri uurimisel ja dokumenteerimisel. Artikkel toob nähtavale vastuolud, mis tekivad kultuuriuurija kahetise rolli tõttu ühest küljest teadlase, sõltumatu vaatlejana, teisest küljest oma töö, tegevuse ja teadmiste kaudu kultuuri looja, edasikandja ja arendajana ning ühtlasi identiteediga seotud ühiskonnaprotsesside kujundajana. Kultuuriuuringutes on praeguseks kujunenud üldiseks standardiks uurija vaatepunkti ja uurimistulemust mõjutavate enesekohaste ja väliste asjaolude teadvustamine, vähem on aga pööratud tähelepanu sellele, milline peaks olema kultuuriteadlase tegevuse oodatav mõju ühiskonnale. Kas teadlase töö eesmärk, tema ülesanne peaks olema kultuurinähtuste ja -protsesside neutraalne dokumenteerimine ja analüüs või peaks ta kirjeldama, vahendama seda, mida ta peab kultuuris väärtuslikuks ja oluliseks, erakordseks või huvitavaks? Kas jätta tähelepanuta kultuuri varjuküljed ja pahupool, nähtused, mida häbenetakse või mis teadlase isikliku moraalitunnetusega vastuollu lähevad, et neid mitte propageerida ja põlistada rahvuskultuuri osana, või tuua need esile kui ühiskonna kitsaskohad? Valikute tegemine on kultuuriuurija töös paratamatu, aga samas on ajalugu näidanud, et teadlase roll kultuuripärandi vahendaja ja edasikandjana mõjutab kirja- ja rahvuskultuuride ajastul oluliselt seda, kuidas ennast rahvana nähakse ja mõtestatakse, mida peetakse oma kultuuri aluseks ja mida mitte. Kas teadlase moraalne kohus peaks olema ennast neist protsessidest distantseerida või peaks ta vastupidiselt pakkuma/vahendama seda, mida peab ühiskonnale kasulikuks või vajalikuks?

Siinse artikli lähtepunktiks on Eesti Rahvaluule Arhiivi (ERA) teadlaste igapäevatöö ning seda eri aegadel ümbritsenud ja suunanud mentaalsed raamistikud: ideoloogia, moraal, traditsioonid, teadusparadigmad, rahastaja ootused, uurija isiklikud läbielamised ja muu. Refleksiivne vaatlus on sündinud vajadusest arhiivi tööd ja tegevust mõtestada, suunata, kavandada ning see on pannud tähelepanelikumalt uurima ka varasemate folkloristide tegevust, selle ajendeid, eesmärke ja mõju. Proovin otsida vastust minu ette kerkinud küsimusele, millist tõde esindavad või peegeldavad kultuuriprotsessis - milles osalevad ühtviisi nii folkloorne suhtlus kui ka humanitaarteadused - tehtud valikud.

\section{Kultuuriloome kui valikuline protsess}

Valikulisus, mis on kogu elusfääri üks olulisemaid mehhanisme, on kultuuriuuringutes jäänud võrdlemisi tähelepanuta. Kultuur, mis on rühmade enesemõtestamise ja identiteediloome põhivahendeid, luuakse valikulises protsessis, 
kus senistele kogemustele tuginedes tõstetakse esile see, mida peetakse väärtuslikuks (vajalikuks, ilusaks, moraalseks), ja laidetakse või vaikitakse maha see, mida peetakse väärtusetuks (tühiseks, koledaks, amoraalseks). Valikute taga on väärtushinnangud, mis määravad, millised kultuuri elemendid, nähtused, teosed korduvad, levivad, saavad tuntuks ja kanduvad ajas edasi ning millised vajuvad unustusse. Kultuuriline väljendus on oluline ja mõjus vahend rühma väärtuste ja uskumuste kehtestamiseks ning see osaleb ühtlasi eri suurusega rühmade identiteedi kujundamisel ja kinnistamisel (nii positiivset kokkukuuluvustunnet luues kui ka vastandumis- ja tõrjumismehhanismide kaudu), indiviidide rühma kaasamise ja sellest väljajätmise protsessides, normaalse (peavoolu) ja marginaalse (äärmusliku) määratlemisel. Rühma täieõiguslikuks liikmeks olemine eeldab, et inimese tegutsemine ja väljendus on kooskõlas rühma põhiväärtustega. Ühiskond koosneb erinevatest rühmadest ja alarühmadest, kelle väärtushinnangud ja ka põhiväärtused ei pruugi kattuda (vt ka Ehala 2018).

Folkloorse suhtlusega antakse vahetult edasi akumuleerunud teadmisi ja kogemusi, mida inimrühmas oluliseks peetakse, ning kasutatakse neid uute olukordade ja nähtuste interpreteerimisel. Folkloori dokumenteerimine, institutsionaliseerimine ning taaskasutamine annab teabele täiendava sümboolse väärtuse, muutes selle teatud inimrühma kultuuripärandi osaks. Kuna nii folkloor kui ka folkloorikogud toimivad ühiskonnas (muu hulgas) autokommunikatsiooni vahendina, millega kinnistatakse rühma uskumusi ja tõekspidamisi (vt Sarv 2018: 12), siis on paratamatu, et nii folkloorseid väljendusi kui ka nendel põhinevaid folkloorikogusid luuakse ja kasutatakse nii, et nad oleks selle rühma uskumuste ja tõekspidamistega kooskõlas. Perepärimus ehk perekonnasiseselt edasi antavad lood lähisugulastest erinevad tihtipeale nendesamade inimeste kohta käivatest külajuttudest, niisamuti nagu ühe rahva või muu rühma liikmete enesepilt erineb eemalseisjate kujutelmadest. Oma rühma (pere, kogukonna, rahva vms) esindajatest antakse edasi pigem positiivset (isegi kangelaslikku) või neutraalset pärimust, moraaliga vastuolus olevad, häbiväärsed, traumaatilised või mingil muul põhjusel sobimatud kogemused vaikitakse maha või distantseerutakse nendest. Tegemist pole neutraalse olukorra või teadmiste kajastusega, vaid valikulise protsessiga, mis teostab (kas varasemale tuginedes või seda eitades) järjepidevalt uut sotsiokultuurilist tegelikkust ning annab oma toimimisega hinnangu sellele, mis on ühiskonnas või kogukonnas väärtuslik ja sobilik ning mis väärtusetu ja sobimatu. Nii nagu jutustaja kohandab oma lugu olukorrale ja publikule sobivaks, jätab ära käesolevas ajahetkes ebaolulised detailid ja võimendab neid, mis publikut köidavad, nii mõjutavad ka kultuuriuurijat teda ümbritsevad paradigmad, ideoloogiad ning ühiskonnakorraldus ja ta püüab leida oma uurimisaineses vaatenurga, mis oodatavat lugejat tema ajas kõnetaks.

Selle jutu ilmestamiseks on mul ehe eksempel oma suguvõsaloost. Vanaema onul oli üks jalg sirge, ei paindunud põlvest. Vanaema rääkis mitmel korral, kuidas ta onu oli noores eas joomase peaga lasknud ennast hobusel koju vedada, mistõttu tema jalg jäi väravapäise taha kinni ja sai viga, ning sündmustest, mis sellele järgnesid: isa oli pahane ega pärandanud oma pojale mitte maad, vaid rahaosaku, poeg läks linna ja hakkas kaupmeheks. Kui rääkisin oma vaaronu lapselapsega, ütles tema, et vanaisa käis Vabadussõjas, 
kuul lendas tal otse põlvest läbi ja nii jäi tal jalg sirgeks. Folkloristina ei huvitagi mind nii väga selle juhtumi tõde kui põhjused, miks ühe fakti kohta (sirge jalg) on levinud kaks niivõrd erinevat lugu, ja mehhanismid, mis sunnivad jutustajat oma loo detaile valima ja teisi kõrvale jätma. Tõlgendus ja valikud pakuvad kohati huvitavamat infotki kui faktid, väljendades tõde kõnelejate mõttemaailma ja väärtushinnangute kohta. Teadustöö puhul tahaksime uskuda, et selle tulemuseks on faktitõde, mis on võimalikult vähe kallutatud seda ümbritsevatest mentaalsetest raamistikest. Kuid vaadates tagasi rahvaluulearhiivi materjalide kujunemis- ja uurimisloole, on ilmne, et see kajastab ühtlasi ajastuomastest ja individuaalsetest väärtushinnangutest mõjutatud teisest tõde, mida suuresti teostatakse valikute - esiletõstmiste ja (tihti märkamatuks jäävate) kõrvalejätmiste - kaudu.

\section{Teadus kui kultuuriprotsessi osa}

Taas kord ajalukku vaadates on ilmne, et teadlased on märkimisväärselt mõjutanud kujutelma eesti rahvast ja kultuurist (vt ka sel teemal läbilõiget humanitaaria eri valdkondadest Keel ja Kirjandus 2018, nr 1-2). Üks eesti kultuuri uurija, kui ta ei taha just olla vaikiv või kuuldamatu teadlane, kujundab seda kujutelma oma kirjutiste, sõnavõttude ja populariseeriva tegevusega nii ehk naa. Teaduskirjutus kui üks kultuurisuhtluse alaliik saab ühed nähtused, sündmused ja faktid esile tõsta, nende tähtsust ja olulisust esile tuua, ja teised maha vaikida. Valikulisus on osalt paratamatu (sest kõigele ei jõua ka teadlane võrdselt tähelepanu pöörata) ja osalt mõjutatud teadlase töö ajalisest ja institutsionaalsest kontekstist, seal kehtivatest väärtussüsteemidest ning teadlase isiklikest eelistustest. Et mitte jääda üldsõnaliseks, toon mõned näited oma uurimisvaldkonnast: regilaulu, rahvaluulekogude ja folkloristika ajaloost ja tänapäevast.

Folkloristidele on hästi teada, et ajaloos on regilaulu suhtutud mitmekesiselt. Varaste saksakeelsete kultuurikirjelduste seas on nii regilaulu ülistavaid kui ka halvustavaid kirjutisi ning nii luterlik kirik kui ka vennastekogudus taunisid regilaulude laulmist. Rahvusliku liikumise üks juhtfiguure ja laulupidude algataja Johann Voldemar Jannsen pilkab ja halvustab 1857. aasta Pärnu Postimehes regilaulu, soovitades need unustada ja omandada „kultuursem” laulmisviis:

- „Aido raido, ellad vennad,” - „Külla neiud, norokessed” ja „Tere ella ämma eita" ja muud nende sarnatsed, nimmetakse ka lauluks, agga ei sanna pitkust, ei õiget viit, ei arro egga otsa; sanna seält, teine teält kokko pandud, nago paigatud torropil, ja se peab laul ollema? Iggal mehhel ommad sannad ja omma viis, teine kõrristab ees, teine kagutab järrele, saggedast kolm nelli kord üht ainust sanna - se peab laul ollema? Seddasuggust laulo voib kõrtsi ukse ees ja külla kige peäl kuulda; agga ta panneb kõrvad ugama ja aiab, nago suitso ving, pea vallutama. [---] Keik saksa rahva laulo-moistus ja laulo-piddud ei aita meile midagi, kui meie isse parrem laulda ei moista, kui se tühhi paljas „aido raido”, mis jodikuttele voime jätta. (Tsiteeritud Laugaste 1963: 178) 
Mõned aastakümned hiljem, 1888. aastal, on Jakob Hurt pidanud oma rahvaluulekogumise üleskutses „Paar palvid eesti ärksamatele poegadele ja tütardele" regilaulu siiski väärtuslikumaks, kutsudes üles inimesi üle kogu Eesti seda kaduvat kunsti ja muudki folkloori jäädvustama, et meil oleks olemas teadmiste kogu eestlaste mineviku kohta (Hurt 1989: 45-56). Kui Jannsen oma kirjutises tunneb veel muret regilaulu ülemäärase tarvitamise pärast, siis Hurda ajal tuleb lauluoskajaid nii mõneski paigas juba otsida. Võib julgesti öelda, et meie teadmised regilaulust tuginevad suuresti Hurda (ja hiljem tema järelkäijate) isiklikule otsusele korraldada üldrahvalik kogumisaktsioon. Praeguseks on regilaulust saanud eesti rahvusliku kultuuripärandi ja eesti identiteedi oluline osa ning seda võib kuulda (küll seatud ja „kultuursemaks" tehtud kujul) isegi laulupeol.

Teiseks, tegeledes regilaulu värsimõõduga, avastasin, et väärtushinnangud võivad mõjutada ka selle justkui puhtmatemaatilise teema käsitlust. 1881. aastal oli soomlane Arvid Genetz sõnastanud kalevalamõõdu reeglid, nn kvantiteedireeglid, ning 1902. aastal avaldatud kirjutises tõdeb soome folklorist Julius Krohn, et kvantiteedireeglid kehtivad ka eesti regilauludes (vt Särg 2005: 94). Soome teadlaste väidetest lähtudes määratletigi terve XX sajandi vältel eesti regilaulu värsimõõtu kui kvantiteerivat trohheust, kõrvalekaldeid sellest käsitleti juhusliku või piirkondliku erandina, pööramata neile suuremat tähelepanu. Mu enese hilisemad värsimõõdu-uuringud näitasid, et koguni poolel Eestimaal on regilaulukirjapanekutes ülekaalus rõhuline värsisüsteem (lühikesed rõhusilbid paigutatakse sarnaselt pikkadega värsiskeemi tugevatesse positsioonidesse) ja kvantiteerivast printsiibist on vähehaaval loobutud (vt põhjalikumalt Sarv 2008). Seega ei saa kuidagi tõeseks pidada laialt levinud ja isegi kooliõpikutesse jõudnud väidet, et eesti regilaulus kehtivad üldiselt kvantiteedireeglid. Ühtse värsimõõdu teooria võeti omaks ilmselt tänu soome teadlaste autoriteedile, aga see sobis ka hästi toetama hõimuideoloogiat ja läänemeresoome rahvaste kultuurilise ühtsuse ideed ning selle kontrollimine oleks arvutieelsel ajastul olnud võrdlemisi töömahukas.

Kolmandaks tahan juhtida tähelepanu folkloorsetele väljendustele, mis on avaliku (või isikliku) moraaliga vastuolus või mis ei sobitu ajastu domineerivate väärtushinnangutega ning on jäänud seetõttu kõrvale folkloori kogumisel, uurimisel ja/või avaldamisel. Jakob Hurt küll rõhutas oma kogumisüleskutsetes, et rahvaluulekogujad paneksid kirja kõik, nii ilusa kui ka inetu, ent samal ajal ei pooldanud ta pastorina ebausu praktiseerimist ega selle populariseerimist, nähes materjalis siiski infoväärtust (Hurt 1989: 25). Nii on seksuaalse sisuga laule ja jutte mõningate kõhklustega küll kirja pandud ja kogutud, kuid allikapublikatsioonides ja uurimustes on teemat mitmesugustel põhjustel enamasti välditud ning arhiivikorralduses jäetud osalt tüpologiseerimata, markeerides sobimatust terminiga lori (vt Kalkun, Sarv 2014). 1950. aastate tsensuurilaine, mille käigus nõukogude inimese moraalikoodeksiga vastuolus olevad folklooripalad rahvaluulekogudest kõrvaldati (vt Kulasalu 2013), pärssis lisaks poliitilistele teemadele küllap ka seksuaalfolkloori talletamist.

On ilmne, et moraal ja väärtushinnangud mõjutavad kultuuri edasiandmist (olgu siis loomulikul teel või institutsionaliseeritud raamides) nii ühiskondlikul kui ka individuaalsel tasandil. 
Kui seksuaalsusega seotud teemad jäävad käsitlemata eelkõige nende kergemeelse konnotatsiooni pärast, siis kergesti jäävad dokumenteerimisest ja uurimustest kõrvale ka tumedamad teemad. Folkloor toimib ühiskonnas sageli allasurutud tunnete (viha, hirmu, depressiooni, ka vägivalla jne) väljendamise kanalina. Tuletagem meelde kas või suurt hulka mõisavastaseid ja orjuslaule, mida eesti regilaulude hulgas on ligi viiendik, või hilisemast ajast näiteks poliitilisi anekdoote. Vägivald inimeste ja loomade vastu on avalikkuses taunitav ja seadusevastane tegevus, mis argikultuuris ja folkloorses suhtluses leiab ühel või teisel moel praktiseerimist ja kajastamist, kuid seda ei kiputa ei dokumenteerima ega esitlema eesti rahvakultuuri osana. Arvo Krikmann on küll välja andnud uurimuse „,Sai hea obaduse vastu obadust”. Löömist ja peksmist märkivad väljendid eesti keeles" (Tartu, 2004), kuid analüüsib materjali eelkõige kui kujundkõne ja keeleainest, süüvimata traditsioonilistesse praktikatesse. Samal ajal annab poeetilise folkloori rikkalikkus meile aimu, kuivõrd olulise teemaga on tegemist. Kunstiline žanr annab ette piirid või reeglid väljendusviisi osas, ühtlasi annab aga vabaduse rääkida olulistest asjadest anonüümselt, rääkija enese seisukohti ja kogemusi varju jättes, ning kunstiline vorm muudab sõnumi mõjusamaks ja meeldejäävamaks. Ainuüksi vanasõnade ja regilaulude põhjal saaks kokku panna väikese käsiraamatu, kuidas ja millal peksta või mitte peksta naist ja lapsi, samal ajal aga puudub igasugune ülevaade sellest, kui levinud on löömine ja peksmine traditsioonilises eesti külaühiskonnas, aga ka linnakogukondades ja perekondades eri aegadel olnud.

Juba seda laadi teemade dokumenteerimine on komplitseeritud. Inimesed ei räägi teistele hea meelega oma kogukonna või rühma sees toimuvast, kui see on avalikkuses taunitav, et mitte kahjustada oma rühma mainet. Samuti ei soovita rääkida asju, mille pärast tuntakse piinlikkust. Kui seda laadi tundlikku infot õnnestubki jäädvustada, siis on dokumenteerija vastutav selle eest, et materjal ei pöörduks teadlasi või rahvaluulekogujaid usaldanud inimeste (või rühmade) vastu. Toon mõned näited oma argivestlustest, kus kirjeldatakse folkloorseid tegevusi, mis žanrilt sobiks kogumikku „Eesti rahvamänge”, kuid avaliku moraali normide tõttu nad sinna ei jõua (mängude peakirjad olen lisanud hiljem).

Konnapuhumine

SV: Me vanasti puhusime kõrrega konna punni tagumikust

MS: Jõhker .. peaasi et lõhki ei puhund ..

SV: Peaaegu. Vastu seina viskasime.

Ogalikkude võidusõit

MS: Räägi ogalikust

SV: Püüad ogaliku kinni ja pistad talle kõrkjajupi selga ora külge korgiks ja siis lased ujuma tagasi. Saab sõpradega võidusõitu teha

MS: Ahah

SV: Ogalikuga saab palju aega surnuks lüüa. Ta on ise täitsa kindel et tal midagi seljas pole

(Redigeerimata väljavõtted digitaalsest eravestlusest.) 
Folkloristid on üsna hästi treenitud ilma hinnanguid andmata kuulama ära erinevaid lugusid, kuid kõhklusi nende arhiveerimisel siiski tekib. Materjali paigutamisega arhiivi olen ühest küljest teadlane, kes jäädvustab ja uurib „nii ilusat kui inetut”, teisest küljest olen aga kultuuri edasikandja, kelle toimimist mõjutavad moraalsed hoiakud ja väärtushinnangud. Kui panen infokillu rahvaluulearhiivi, muutub see automaatselt eesti kultuuripärandi osaks ja mul kaob kontroll selle üle, kuidas ja mis eesmärkidel seda teavet edaspidi kasutatakse. ERA-s on küll materjalile võimalik rakendada kasutuspiiranguid ja vajadusel seda ka tehakse, kuid sel juhul on materjali kasutus ja kasu sellest samuti piiratud.

Mall Hiiemäe (snd Proodel) on arhiivi jaoks kirja pannud mõned samalaadsed karjapoiste mängud, samas on lisatud kas esitaja või kirjapanija loomadega mängimist õigustav selgitus.

\section{Parmuveski}

Suvel karjas olles võttis karjapoiss $5-10 \mathrm{~cm}$ pikkuse kasteheinakõrre, lõhestas selle ühe otsa neljaks ja torkis need otsad neljale parmule taha. Nii saadi parmuveski. Mängisid peamiselt poisid. Mäng tundub julmana, kuid tuleb arvestada, et parmud on suvel karjase kõige kurjemad vaenlased.

(EKM ERA, EKRK I 19, 321 (6) < Iisaku - Mall Proodel (1956/7))

\section{Konnapüss}

Kui karjased said kätte kärnkonna, panid nad selle lauaklopi (või puuhalu) peale, laua aga näit. kännu peale. Nüüd löödi kaikaga vastu teist lauaotsa, nii et konn lendas kõrgele õhku. Konnapüssi tegid peamiselt poisid. Ka sõnnikuveo ajal leitud kärnkonn anti karjapoisile „püssi tegemiseks”, sest kärnkonna peeti halvaks ja roojaseks loomaks, kellel laudast „pole midagi otsida”.

(EKM ERA, EKRK I 19, 343 (15) < Iisaku - Mall Proodel (1956/7))

Ilmselgelt kuulub eesti rahvatraditsiooni tumedamasse nurka nii loomapiinamine, koolikiusamine, rahvuskonfliktid, alkoholism kui ka perevägivald. Seda laadi, avalikus diskursuses taunitavad (ja osalt ebaseaduslikud) nähtused on aga rahvakultuuri osana äärmiselt puudulikult dokumenteeritud ning ka rahvusliku kultuuripärandi vormimise protsessis tihti kõrvale jäetud. Samuti on jäänud suuresti dokumenteerimata selliste rühmade ja kogukondade kultuur, millega folklorist kokku ei puutu ja mis talle isiklikult võivad olla vastumeelsed, hirmutavad või eemaletõukavad.

Rahvaluule dokumenteerimisel, uurimisel ja avaldamisel on välditud teatud teemasid,

- et mitte minna vastuollu valitseva ideoloogia, avaliku moraali ja muude avalikkuses kehtivate normidega;

- et mitte kahjustada asjasse puutuvate isikute või rühmade mainet;

- et teadlane ei peaks oma töös (kultuuri edasi kandes) tegutsema omaenese vaadete, uskumuste ja moraali vastaselt;

- et mitte kahjustada teadlase, institutsiooni või distsipliini mainet ja tõsiselt võetavust (uurides teemasid, mis ei sobi ajastu normide või paradigmadega); 
- et materjalid oleksid sobivad kasutamiseks hariduses, kultuuriloomes, esitlemiseks rahvusliku kultuuripärandina.

\section{Teadlase vastutus ja valikud kultuurimälu loomisel}

Nagu eelnevast nägime, ei seisne kultuuri edasiandmisel tõde mitte üksnes tegelikkuse sündmuste või eelnevalt öeldu reprodutseerimises. Tõde seisneb ka iga edasiandja valikutes ja väärtushinnangutes, millega ta mõjutab kultuuriprotsessi ja osaleb selles. Kultuuriteadused oma kahetise rolliga on keerulises olukorras, ühest küljest uurides kultuuri ja selles toimuvaid protsesse, teisest küljest oma teadustegevusega neis ise osaledes.

Rahvaluulearhiivi roll ühiskonnas on tagada avalikkusele juurdepääs kultuurilist minevikku ja paigapärimust kätkevale infole. Arhiivi teadlased teevad otsuseid, milliseid kaasaja mitteinstitutsionaalse kultuuri nähtusi dokumenteerida, otsustavad, kuidas olemasolevaid kogusid süstematiseerida, mida ja kuidas avaldada, ning kogusid tundvate ekspertidena ka aitavad neid materjale oma uurimuste ja tutvustustegevustega arusaadavaks teha ja mõtestada. Need tegevused moodustavad osa sellestsamast kultuuriprotsessist, mida me uurime. Teadlastena peame paratamatult tegema valikuid, lähtudes sellest, mis on oluline praegusaja ühiskonna jaoks, ja ennustama, milline teave käesoleva aja kultuuri kohta võiks olla väärtuslik tuleviku inimestele.

Eesti põhiseaduse preambul sätestab, et Eesti riik peab tagama eesti rahvuse, keele ja kultuuri säilimise läbi aegade. Vaikimisi võiks eeldada, et selle põhiseadusliku kohustuse täitmise eest peavad hea seisma ka riiklikud mäluasutused, teiste seas Eesti Kirjandusmuuseum (kuhu kuulub Eesti Rahvaluule Arhiiv), tehes otsuseid ja valikuid, mida koguda, säilitada ja esitada kui kultuuri. Siin tekibki mitmeid küsimusi. Milline on see osa kultuurist, mida peaksime kaitsma? Kas käsitleda nähtusi, mis on seadustega ja/või kaasaja avaliku moraali normidega vastuolus kui argikultuuri osa või kui väärnähtusi? Kas peaksime ka neid nähtusi „kaitsma” ja esitlema rahvusliku kultuuripärandina? Kas selleks, et neid mitte propageerida eesti kultuuri osana, peaksime need avalikkuse eest varjule jätma? Kas teades, et folkloorne väljendus toimib ühiskonna kitsaskohtadel ventiilina ja allasurutud tunnete (viha, vägivalla, hirmu, depressiooni jne) väljendamise kanalina, peaksime neid nähtusi hoopis tähelepanelikumalt dokumenteerima ja analüüsima kui väärtuslikku teabeallikat, mis võib anda vihjeid ühiskonna probleemide kohta?

Folkloori pärandistumisprotsessi kõikides etappides - dokumenteerimisel, arhiveerimisel, süstematiseerimisel, uurimisel, avaldamisel ja taaskasutamisel - võime näha valikulisust, mis kehtestab erinevate ideoloogiate, institutsioonide, isikute väärtushinnanguid erinevatest eesmärkidest johtudes. Teemad, mis on vastuolus avaliku moraaliga või ei sobitu ajastu domineerivate väärtushinnangutega, jäävad tihti kõrvale ning iga järgmise valikuga muutub pilt rahvakultuurist järjest ümmargusemaks ja ilusamaks. Tulemuseks on kultuuriprotsessis loodud idealistlik ja kaunis kujutelm rahvusest ja tema kultuurist, kus piinlikkust tekitavad või muidu sobimatud seigad on maha vaikitud. Nagu artikli alguses selgitatud, on see igati tavapärane kultuuri edasiandmise mehhanism. Kultuuri üks oluline funktsioon ongi kogukonna 
väärtuste ja normide kehtestamine, kujundlikult ja mõjuvalt. Ühiskonnas on aga ka need inimesed, kelle lood on maha vaikitud, sest need ei sobi, ja kelle elukogemus ei ole ühitatav ilusaks puhastatud rahvuskultuuriga.

Peeter Torop on nimetanud humanitaar- ja sotsiaalteadusi tagasisideteadusteks, mille üks missioone on anda kultuurile enesemõistmise võime (Torop 2011: 8). Sellega eeldab Torop, et kultuuriuurija peaks töötama ühiskonna heaks, ning riiklikult rahastatud teaduse puhul on see mõistetav. Teadlased peavad lahendama dilemma, kuidas käituda juhul, kui neil on endil uurimisobjekti suhtes mingisugused tunded või moraalsed hinnangud. Nägime eespool, et valikute tegemine on vältimatu, kuid kuidas ja mille alusel peaks teadlane oma valikuid tegema, et ühest küljest säilitada neutraalne objektiivsus (mitte hakata ellu rakendama oma moraalset, ideoloogilist või poliitilist agendat või eelistusi) ja teisalt olla kasulik ühiskonnale? Millisel moel peaks teadlane oma teadmisi ja kompetentsust kasutama ühiskonna vajaduste ja kitsaskohtade lahendamiseks? Millistest põhimõtetest lähtudes osalema kultuuri kujundamises? Millistest väärtustest lähtuvalt millist teavet kõrvale jättes ja millist esile tõstes?

Prominentse kirikuõpetaja ja teadlasena suutis Jakob Hurt omal ajal teha midagi enneolematut: anda hääle kogukonnale, kes tolleaegses saksa ja vene kõrgema klassi hallatavas avalikus ruumis ja ühiskonnakorralduses oli kõrvaline (meenutagem näiteks, et esimene eestlasest linnapea asus ametisse aastal 1901). Ühtlasi lõi rahvaluulekogumise aktsioon terviklikkust ja sidusust Eesti ühiskonnas: suulise ja kirjakultuuri esindajate vahel, haritlaste ja mitteharitlaste vahel, maa- ja linnarahva vahel, eestlaste ja muulaste vahel. Ka praegu peaks küsima, millised on kogukonnad, kelle hääl avalikku ruumi ei jõua või ei sobi, millised on meie kodutute, kriminaalide, luuserite, küüditajate ja hobusevaraste lood, pärimus ja kultuuripraktikad ning kuidas neid sobitada Eesti kultuuripilti, kus on suurimad lõhed Eesti ühiskonnas ja kuidas luua mõistmist üle nende lõhede.

Artikkel on valminud Haridus- ja Teadusministeeriumi rahastatud projekti IUT 22-4 „Folkloor kultuurilise kommunikatsiooni protsessis: ideoloogiad ja kogukonnad" raames, seda on toetanud Euroopa Liit Euroopa Regionaalarengu Fondi kaudu (Eesti-uuringute Tippkeskus).

\section{Arhiiviallikad}

EKM ERA - Eesti Kirjandusmuuseumi Eesti Rahvaluule Arhiiv EKRK - Tartu Ülikooli eesti kirjanduse ja rahvaluule kateedri kogu

\section{Kirjandus}

Ehala, Martin 2018. Identiteedimärgid. Ühtekuuluvuse anatoomia. Tallinn: Künnimees.

H u r t, Jakob 1989. Mida rahvamälestustest pidada. Artiklite kogumik. Koost Ülo Tedre. Tallinn: Eesti Raamat. 
Kalkun, Andreas, Sarv, Mari 2014. Seks ja poeetika: regilaulu peidus pool. Vikerkaar, nr 4-5, lk 91-108.

$\mathrm{Kul}$ a s a l u, Kaisa 2013. Ropp ja riigivastane. Rahvaluulekogude tsenseerimisest Eestis hilisstalinismi perioodil. Magistritöö. Tartu: Tartu Ülikool. http://hdl. handle.net/10062/32411 (29. VIII 2019).

Laugaste, Eduard 1963. Eesti rahvaluuleteaduse ajalugu. Valitud tekste ja pilte. Tallinn: Eesti Riiklik Kirjastus.

S a rv, Mari 2008. Värsimõõt ja hõimutunded: kvantiteedireeglid eesti regilaulus. - Keel ja Kirjandus, nr 6, lk 409-420.

S a rv, Mari 2018. Rahvusteadused kui iseenda mõtestamine. - Keel ja Kirjandus, nr 1-2, lk 11-14.

S ärg, Taive 2005. Eesti keele prosoodia ning teksti ja viisi seosed regilaulus. (Dissertationes folkloristicae Universitatis Tartuensis 6.) Tartu: Tartu Ülikooli Kirjastus.

T o r o p, Peeter 2011. Tõlge ja kultuur. Tallinn-Tartu: Tartu Ülikooli Kirjastus.

Mari Sarv (snd 1972), PhD, Eesti Kirjandusmuuseumi vanemteadur (Vanemuise 42, 51003 Tartu), mari@folklore.ee

\section{The moral choices of a researcher in the process of creating cultural memory}

Keywords: folklore, archives, cultural process, national culture, morality

The article aims to analyse, on the example of folkloristics, a researcher's choices in studying and documenting culture. The article reveals the contradictions arising from the dual role of a cultural researcher who, on the one hand, should function as an independent observer, but on the other hand their work, activities and knowledge make them a creator, transmitter and developer of culture, as well as a designer of identity-bound social processes. The modern standards of cultural studies require an awareness of the extrinsic and intrinsic factors affecting the researcher's perspective and the research outcome, while less attention has been paid to the social impacts expected from the researcher. Should their task consist in neutral documentation and analysis of cultural phenomena and processes or should they describe and mediate first and foremost what they regard as essential and valuable, extraordinary or interesting? Should they ignore the negative aspects of culture, that is, whatever is considered reprehensible or contradictory to their personal sense of morality, in order to avoid promoting and perpetuating such phenomena as part of national culture, or should those, on the contrary, be highlighted as bottlenecks in the community? In the work of a cultural researcher, choices are, of course, inevitable, but history has shown that in the era of literary and national cultures the role of a researcher as a bearer and mediator of cultural heritage has a profound impact on our self-image as a people, including on what we see as the foundation of our culture and what we do not.

Mari Sarv (b. 1972), PhD, Estonian Literary Museum, Senior Researcher (Vanemuise 42, 51003 Tartu), mari@folklore.ee 